there is a dual carriage way and it is emphasized how necessary it is to treat dual carriage ways as if they were two separate roads. When the dual road bends away in the country from the 'roundabout', the lighting points become closer on the outside of the bend. Cross-road lighting treatment is also shown in several places. Lights here are arranged just beyond the crossing on the left-hand side as the traffic proceeds; then traffic moving at right angles and pedestrians preparing to cross the road become clearly visible. In addition, photographs are shown to illustrate the more important features demonstrated by the model and suggested in the recom. mendations. A fuller description of this model is given in the Osram G.E.C. Bulletin of May 1938.

\section{Short-Circuit Testing Stations}

Aвour ten years ago it was found necessary to build short-circuit testing stations in order to find out the true rating for a large switch or currentbreaker. In order to find out how a switch will break a large electric current at a low voltage or a current at a very high voltage, different methods have to be used and special large and expensive devices are necessary. It is very unsatisfactory to assign nominal ratings based on theoretical design considerations and experience gained by similar apparatus. The International Electrotechnical Commission has now published a specification for the short-circuit testing of circuitbreakers, and manufacturers have to issue a certificate with the apparatus stating that it has passed the required proving tests. Eight years ago Messrs. Reyrolle and Co. built the first short-circuit testing station at Hebburn-on-Tyne and since then, two more have been erected in Great Britain and others are being constructed or are under contemplation. According to the Electrical Power Engineer of December last, the certification of switches is not exclusively confined to those manufacturers who own testing stations in whole or in part. The facilities of all the British proving stations are open to other manufacturers for making tests. This entails a definite assurance from the testing stations of privacy in testing and secrecy of results of experiments making so much noise and requiring so large a space. All work is carried out on apparatus under a reference number, the manufacturer's name being omitted and also the designation of the apparatus. During testing all entrances to the station are locked. A separate office is provided for the use of customers wishing to discuss reports. Sometimes cinematograph films of the tests are shown at these offices.

\section{Paris Academy of Sciences}

The "Annuaire" of the Paris Academy of Sciences has for some years past included a biographical index of past and present members and correspondants of the Academy. In this year's volume (Paris : Gauthier Villars, 1938), this index is considerably enlarged; notes have been added indicating the subject or subjects in which each individual was particularly interested, and the list of names has been augmented by including the members of the older body, the
Royal Academy of Sciences (1666-1795). A paper read by Prof. Alfred Lacroix, one of the permanent secretaries of the Academy, at the meeting held on January 4 last (C.R., 206, 23), explains the changes that have been made and describes briefly the various previous attempts to provide a complete statement of past and present members of the Academy. The archives of the Academy now have a separate file for each individual who has been connected with it, and every effort is being made, by searching national, parish and other records, to ensure that biographical details are correct. Further, by dint of most painstaking research, the documents relating to the proceedings of every meeting of the Academy, apart from biographical material, have been classified and they are now also arranged in files, one to each meeting from that of " 6 nivôse an IV" (December 27, 1795). As regards meetings of the Royal Academy of Sciences, there are in the archives 109 large folio volumes of Proces verbaux prepared by the five successive permanent secretaries, J.-B. du Hamel, Fontenelle, Dortous de Mairan, Grandjean de Fouchy and Condorcet, which go back to the first meeting on December 22, 1666. The total number of men of science who have belonged to the Academy since 1666 is 2,071 (members, 992; correspondants, 1,079); it possesses nearly sixteen hundred autographs and about the same number of portraits.

\section{Curtis's Botanical Magazine}

A COMPLETE volume of this beautifully illustrated botanical periodical has recently been published in one cover (Curtis's Botanical Magazine, 147. London : Bermard Quaritch, Ltd. 63s, net). This is to fill a gap in the series created by the non-appearance of a volume in 1921. At the end of 1920, publication of the Magazine ceased, and it seemed possible that the copyright would pass to an owner in the United States; but in 1921, the Royal Horticultural Society was presented with the copyright through the generosity of subscribers. The gap thus created in the series has now been filled through the generosity of Mr. Reginald Cory, and the volume is dedicated in accordance with his wish to Sir Isaac Bayley Balfour, Sir David Prain and Sir Frederick Moore in recognition of their services to botany and horticulture. Fifty-seven plants are described and beautifully illustrated, including eleven species of Rhododendron, fifteen of Primula and four of Gentiana. Plants from all parts of the world are described in the Magazine; but in this volumeChinese plants take pride of place-thirty-eight species; five South African species are described and the rest come from countries so far apart as Peru, Siberia, Japan and Tibet. The method familiar to all readers of this periodical is adopted. The history of each species, so far as it is known, is briefly given, and this is followed by a detailed description of morphology (especially floral) and distribution. The beautifully coloured illustrations of each plant described are, of course, the main feature of the volume. The authoritative nature of the text cannot be questioned. Here one notices such familiar contributors as $O$. Stapf (seventeen species alone and ten in collaboration either with 